\title{
Detailed Investigation of Surface Passivation Methods for Lifetime Measurements on P-Type Silicon Wafers
}

\author{
Kevin L. Pollock, Johannes Junge, and Giso Hahn
}

\begin{abstract}
The effect of five different common surface passivation techniques on the measured bulk lifetime values of multiand monocrystalline p-type silicon wafers was investigated. Mono[Czochralski $(\mathrm{Cz})$ and floatzone (FZ)] and multicrystalline [mc and edge-defined film-fed growth (EFG)] silicon wafers were either deposited with a dielectric passivating layer of $\mathrm{SiN}_{x}, \mathrm{Al}_{2} \mathrm{O}_{3}$, or amorphous silicon (a-Si) or were passivated chemically with 0.08 M iodine-ethanol (IE) or 0.07 M quinhydrone-methanol (QM) solutions. The temporal stability of annealed and nonannealed $\mathrm{Cz}$ wafers that were passivated with $Q M$ and IE was tested. The lifetime values of $\mathrm{EFG}$, mc, and $\mathrm{FZ}$ wafers that were subjected to repeated QM passivation and mc wafers that were subjected to IE passivation without a surface etching between passivations were found to decrease with each passivation. Lifetime values of a set of $11 \mathrm{mc}$ wafers that were passivated with $\mathrm{Al}_{2} \mathrm{O}_{3}$ were found to decrease about $30 \%$ after a period of four weeks in darkness. The decrease was reversible by annealing the samples. The lifetime values of annealed $\mathrm{Cz}$ samples that were passivated with $\mathrm{Al}_{2} \mathrm{O}_{3}$ and a-Si were found to decrease by $>20 \%$ within $5 \mathrm{~h}$ of annealing. Subsequent tests on $200-\Omega \cdot c m ~ F Z$ material did (for a-Si) and did not (for $\mathrm{Al}_{2} \mathrm{O}_{3}$ ) show surface passivation degradation over this time period. Neighboring mc wafers were passivated dielectrically or wet chemically with IE or QM and characterized with photoluminescence imaging. All mc wafers that were subjected to dielectric passivation methods that include annealing at $400{ }^{\circ} \mathrm{C}$ displayed a greater area of high lifetime values but fewer areas of very high lifetime values, providing visible evidence of internal gettering and/or defect redistribution.
\end{abstract}

Index Terms-Photoconductance, silicon wafers, surface passivation.

\section{INTRODUCTION}

D ANGLING silicon bonds on silicon wafer surfaces are a major source of recombination centers and must be passivated if meaningful bulk lifetime measurements are to be obtained. Good temporal passivation stability, high effective lifetime values (low surface recombination velocity), and minimal effects on the wafer bulk (e.g., reduction of $\left[\mathrm{Fe}_{i}\right]$ by clustering at elevated temperatures) would be provided by an ideal passivation method for wafer characterization. In practice, different

K. L. Pollock was with the Department of Physics, University of Konstanz, 78457 Konstanz, Germany. He is now with the University of California, Berkeley, CA 94720 USA (e-mail: kevlarp@berkeley.edu).

J. Junge and G. Hahn are with the Department of Physics, University of Konstanz, 78457 Konstanz, Germany (e-mail: johannes.junge@uni-konstanz. de; giso.hahn@uni-konstanz.de). passivation methods provide these qualities to, respectively, better or worse degrees. The dielectric passivation methods $\mathrm{Al}_{2} \mathrm{O}_{3}$, $\mathrm{SiN}_{x}$, and a-Si are investigated in this paper along with the wet chemical passivation methods quinhydrone-methanol (QM) and iodine-ethanol (IE). Thermal and plasma-assisted atomic layer deposition (ALD) of $\mathrm{Al}_{2} \mathrm{O}_{3}$ has shown promise as a new method of wafer passivation in the laboratory and industry [1]. $\mathrm{SiN}_{x}$ is widely used in industry for passivation of solar cells because of its dual antireflection and surface passivation properties [2]. Passivation with a-Si allows deposition and annealing temperatures of $300{ }^{\circ} \mathrm{C}$ or less (see [3]). Wet chemical passivation methods such as IE and QM offer the advantage of greater reversibility, as wafers can be passivated mid-processing without depositing a dielectric layer that subsequently must be etched away, but also have been seen to degrade wafer quality after wafer rinsing (see Section III). Since the development of IE passivation [4], [5] as a viable method for silicon wafer surface passivation, QM has been shown to offer more stable passivation than IE with better passivation quality in most cases [6], [7]. Specific process conditions are extremely important in the field of silicon wafer passivation, making the results in this paper specific to the processes and conditions described.

\section{EXPERIMENTAL DETAILS}

All wafers that are used in this investigation are p-type wafers. $\mathrm{Al}_{2} \mathrm{O}_{3}$ deposition was performed at $200^{\circ} \mathrm{C}$ using remote plasma ALD in a FlexAL tool from Oxford Instruments using trimethylaluminum and oxygen plasma, resulting in a refractive index of 1.7 at $630 \mathrm{~nm}$. All $\mathrm{Al}_{2} \mathrm{O}_{3}$-passivated wafers were annealed after deposition at $400{ }^{\circ} \mathrm{C}$ for $30 \mathrm{~min}$ to activate the passivation. 30-nm-thick intrinsic a-Si layers were deposited on all a-Si-passivated samples at $225^{\circ} \mathrm{C}$ by remote plasma enhanced chemical vapor deposition (PECVD) in a PlasmaLab 100 tool from Oxford Instruments using $\mathrm{SiH}_{4}$ gas, resulting in a refractive index of 3.95 at $630 \mathrm{~nm}$. All a-Si wafers were annealed after deposition at $300^{\circ} \mathrm{C}$ for $10 \mathrm{~min}$. $\mathrm{SiN}_{x}$ deposition using $\mathrm{SiH}_{4}$ and $\mathrm{NH}_{3}$ was performed at $450{ }^{\circ} \mathrm{C}$ using a low frequency direct PECVD method with deposition parameters similar to industrial solar cell application, resulting in a refractive index of around 2.1 at $600 \mathrm{~nm}$ (Centrotherm E2000 HT, $40 \mathrm{kHz}$ ). QM and IE experiments were conducted using a 0.07-M quinhydrone solution in methanol and a $0.08-\mathrm{M}$ iodine solution in ethanol, respectively. Wafers in wet chemical passivation trials were first treated in a warm $\left(\sim 80{ }^{\circ} \mathrm{C}\right) 3: 1 \mathrm{H}_{2} \mathrm{SO}_{4}: \mathrm{H}_{2} \mathrm{O}_{2}$ solution for 10-15 min; then, after a $\mathrm{DI} \mathrm{H}_{2} \mathrm{O}$ rinse, they were dipped in $5 \%$ hydrofluoric acid (HF) for $1 \mathrm{~min}$, followed by another DI $\mathrm{H}_{2} \mathrm{O}$ rinse. The passivation was achieved by sealing the wafer in a plastic bag with a small amount of the passivating solution. 
All wafers were etched in a CP6 damage etch bath solution $(50 \% \mathrm{HF}, 99 \%$ acetic acid, $65 \%$ nitric acid solutions in a 11:26:163 ratio), creating a flat wafer surface (no surface texturing present, as is typically used for the front side of solar cells), and then cleaned prior to passivation using standard industry cleaning procedures $(3 \% \mathrm{HCl}$ and $1 \% \mathrm{HF}$ solutions). If denoted as RCA, wafers were additionally cleaned using the RCA cleaning method [8], [9]. All Czochralski (Cz) wafers were degraded for $17 \mathrm{~h}$ under illumination at $45^{\circ} \mathrm{C}$ prior to passivation trials to ensure uniform development of boronoxygen (BO) recombination centers in each wafer. All pregettered multicrystalline $(\mathrm{mc})$ wafers were subjected to a one-step $\mathrm{POCl}_{3}$ emitter diffusion (for lab-type solar cells) at temperatures around $820^{\circ} \mathrm{C}$ after $\mathrm{CP} 6$ etching, resulting in a sheet resistance of $80-100 \Omega /$ sq. Quasisteady-state photoconductance (QSSPC) measurements were performed using a WCT-120 wafer lifetime testing instrument from Sinton Consulting, with optical constants derived from in-house measurements and using an intrinsic carrier concentration $n_{i}=8.6 \times 10^{9} \mathrm{~cm}^{-3}$. Transient mode QSSPC measurements exhibiting lifetime values above $1 \mathrm{~ms}$ were an average of six successive flashes with a delay of $1 \mathrm{~s}$ between flashes; all other QSSPC measurements were single flash measurements. Microwave-detected photoconductance decay $(\mu \mathrm{PCD})$ measurements were carried out using a Semilab WT-2000 $\mu$ PCD device.

\section{RESULTS}

Each individual data point in each graph represents a single measurement of a single wafer, except Fig. 4, in which each data point is an average of 11 measurements. The CP6 etching procedure may lead to slightly different flatness of the wafer surface for different materials, which might have an influence on surface passivation. Therefore, floatzone (FZ) wafers are only compared with $\mathrm{FZ}$ wafers, $\mathrm{Cz}$ to $\mathrm{Cz}$, etc.

\section{A. Passivation Stability Issues}

Six Cz wafers (B-doped, $2.5 \Omega \cdot \mathrm{cm}, 160 \mu \mathrm{m}$ ) were passivated with QM (three wafers) or IE (three wafers). One wafer from each group of three was annealed in darkness at $200{ }^{\circ} \mathrm{C}$ for $15 \mathrm{~min}$ before passivation, whereas the remaining four samples were passivated without a prior anneal step. Time-resolved QSSPC lifetime values were measured directly after passivation. QM and IE samples that were not subjected to the anneal step showed a flat trace of low lifetime values. The annealed QM sample exhibited a characteristic [6] passivation trace in which the measured lifetime values rose steeply within 15 min of passivation and, thereafter, remained stable. The annealed IE sample also showed a characteristic [6] passivation trace in which the highest lifetime value was achieved at $t=0$, after which the measured lifetime values decreased (see Fig. 1). Although both annealed wafers were subjected to BO complex formation, only the IE-passivated annealed wafer showed a significant decrease in measured effective lifetime. The low lifetime values of the nonannealed samples are attributed to $\mathrm{BO}$ recombination centers that are formed during the prepassivation illuminated degradation process (see Section II).

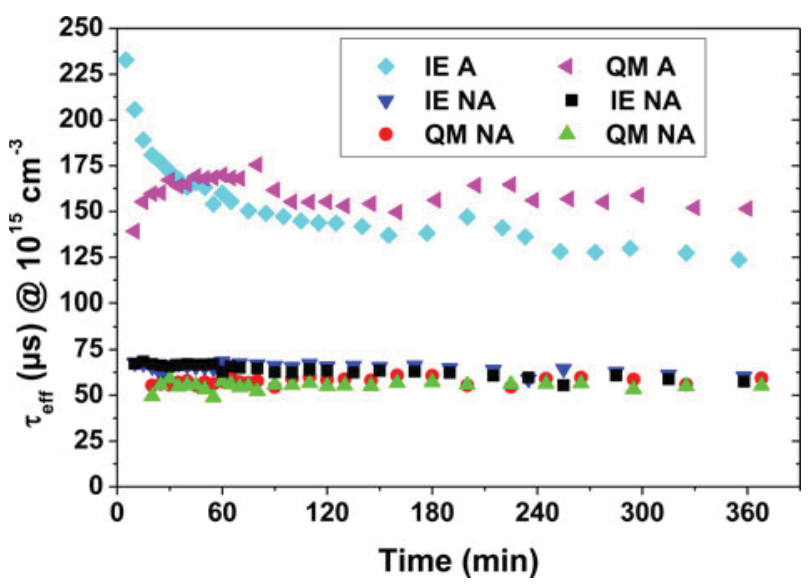

Fig. 1. Time-resolved QSSPC lifetime measurements (quasisteady-state mode) of $\mathrm{Cz}$ wafers that were passivated with wet chemical passivation methods. All wafers were subjected to light-induced degradation before passivation to ensure uniform BO complex creation. Samples that are marked with "A" were subjected to a $15 \mathrm{~min} 200^{\circ} \mathrm{C}$ anneal step in darkness prior to passivation, in contrast with samples that are marked with "NA," which were not annealed.

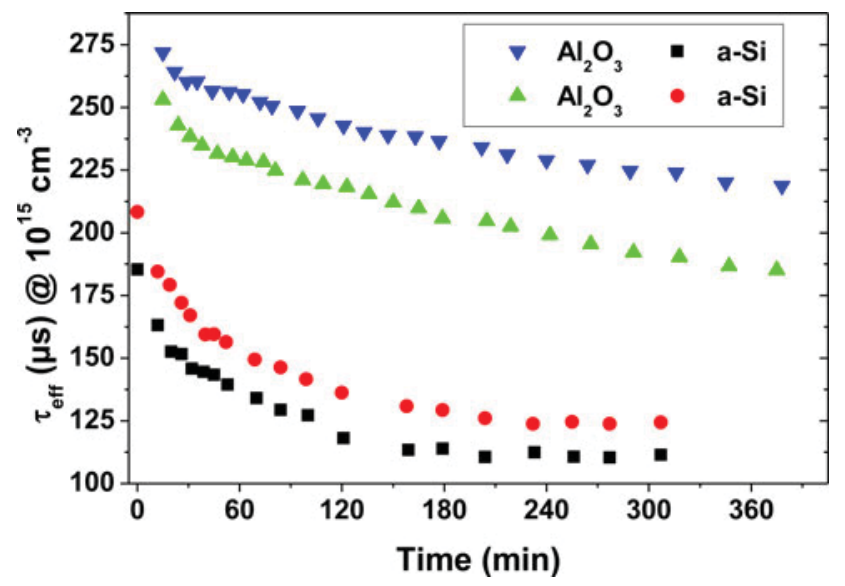

Fig. 2. Time-resolved QSSPC lifetime measurements (a-Si wafers: Quasisteady-state mode; $\mathrm{Al}_{2} \mathrm{O}_{3}$ wafers: Transient mode) of $\mathrm{Cz}$ wafers that are passivated with dielectric methods measured directly after annealing.

Four $\mathrm{Cz}$ silicon wafers (B-doped, $2.5-\Omega \cdot \mathrm{cm}, 160 \mu \mathrm{m}$ ) were passivated by dielectric passivation methods (two with $\mathrm{Al}_{2} \mathrm{O}_{3}$ and two with a-Si), as described previously. Time-resolved QSSPC lifetime measurements that were conducted after the passivation layer deposition and annealing step revealed a steady decrease in lifetime values for all samples within $5 \mathrm{~h}$ of the first measurement, which was conducted immediately after the sample annealing (see Fig. 2). Samples that are passivated with a-Si showed a faster rate of lifetime degradation than samples that are passivated with $\mathrm{Al}_{2} \mathrm{O}_{3}$.

To better elucidate the cause of the lifetime decrease shown in Fig. 2, eight FZ samples (B-doped, 200- $\Omega \cdot \mathrm{cm}, 220 \mu \mathrm{m}$ ) were deposited with $\mathrm{Al}_{2} \mathrm{O}_{3}$ or a-Si in groups of four. Within each group of four, two wafers were cleaned with the $\mathrm{HCl} / \mathrm{HF}$ cleaning method and two were additionally cleaned by applying the RCA method. The wafers were annealed as described previously, and time-resolved QSSPC lifetime values were measured. The $\mathrm{Al}_{2} \mathrm{O}_{3}$ passivation displayed temporal stability, with 


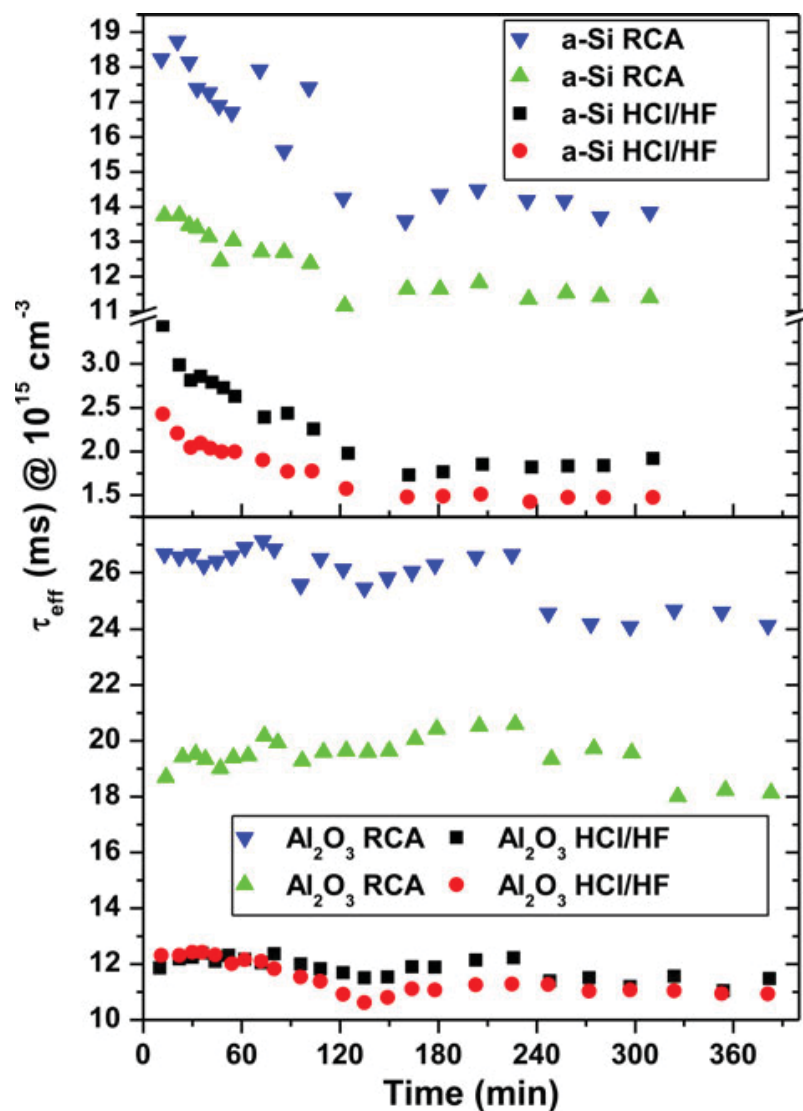

Fig. 3. Time-resolved QSSPC lifetime measurements (transient mode) of FZ samples cleaned with the $\mathrm{HCl} / \mathrm{HF}$ and RCA methods and passivated with a-Si (top) and $\mathrm{Al}_{2} \mathrm{O}_{3}$ (bottom) measured directly after the anneal.

an average lifetime value decrease of $5 \%$ after $5 \mathrm{~h}$. The a-Si passivation was not as stable, with an average lifetime value decrease of $32 \%$ after 5 h (see Fig. 3). Since the measurements were made with FZ wafers, the degradation which is seen cannot be due to $\mathrm{BO}$ complex formation, and, thus, must be because of degradation of the surface passivation layer. This suggests that the degradation on $\mathrm{Cz}$ wafers shown in Fig. 2 is mainly because of $\mathrm{BO}$ complex formation in the $\mathrm{Al}_{2} \mathrm{O}_{3}$ samples, and a combination of $\mathrm{BO}$ complex formation and surface passivation degradation in the a-Si samples, which may explain why the lifetime values of the a-Si samples that were shown in Fig. 2 decreased significantly faster than the lifetime values of the $\mathrm{Al}_{2} \mathrm{O}_{3}$ samples in the same figure.

Six mc silicon wafers (B-doped, $1-\Omega \cdot \mathrm{cm}, 300$ and 180 $\mu \mathrm{m})$ were dielectrically passivated in sets of two with $\mathrm{Al}_{2} \mathrm{O}_{3}$, a-Si, or $\mathrm{SiN}_{x}$, as described previously. Minority charge carrier lifetime values were recorded by QSSPC at an injection level of $2 \times 10^{15} \mathrm{~cm}^{-3}$ directly after annealing. The wafers were then stored in a dark environment for 13 days and lifetime values were remeasured. $\mathrm{Al}_{2} \mathrm{O}_{3}$ and a-Si samples displayed a significant decrease in lifetime values from day one to day 13, whereas $\mathrm{SiN}_{x}$-passivated samples displayed no decrease in lifetime values in the same time period. After 26 days in a dark environment, the a-Si samples were remeasured before and directly after repeating the initial annealing step. After the second annealing step, lifetime values increased to near or over the original values (see Table I).

To further investigate the $\mathrm{Al}_{2} \mathrm{O}_{3}$ degradation seen in Table I, 11 pregettered $\mathrm{mc}$ (B-doped, $1 \Omega \cdot \mathrm{cm}, 180 \mu \mathrm{m}$ ) wafers were coated with $\mathrm{Al}_{2} \mathrm{O}_{3}$ and annealed as described previously, and QSSPC lifetime measurements (injection $10^{15} \mathrm{~cm}^{-3}$ ) were obtained over a period of 57 days (see Fig. 4). Wafers were kept in darkness between measurements. After 27 days, lifetime measurements revealed an average drop of $60 \mu \mathrm{s}$, to $71 \%$ of the original lifetime value. All wafers were then annealed a second time, after which the average lifetime value rose to $103 \%$ of the value that was measured on day one. 29 days after the second anneal, lifetime measurements showed an average drop of $75 \mu \mathrm{s}$, to $65 \%$ of the value that was measured after the annealing on day 28. The mechanism of the $\mathrm{Al}_{2} \mathrm{O}_{3}$ degradation on mc material is up to now unclear, pending further investigation.

$\mu \mathrm{PCD}$ minority charge carrier bulk lifetime values of an mc silicon EFG wafer (B-doped, $2.5 \Omega \cdot \mathrm{cm}, 280 \mu \mathrm{m}$ ) which had been subjected to repeated QM passivation trials were determined. The wafer was passivated with QM as previously described in Section II and lifetime values were measured, after which the wafer was rinsed of quinhydrone using a four-beaker "methanol cascade" method [10]. The process was repeated five times without cleaning using an $\mathrm{HCl} / \mathrm{HF}$ process and without chemically etching silicon off of the wafer surface between each passivation treatment. The average measured lifetime value of the wafer decreased with each trial (see Fig. 5). This decrease is attributed to quinhydrone residues that stay on the wafer even after a methanol rinsing step and which can diffuse into the surface layer of the wafer.

To further elucidate the trend of decreasing lifetimes with repeated QM passivation, two mc wafers (B-doped, $1 \Omega \cdot \mathrm{cm}$, $200 \mu \mathrm{m})$ and two FZ wafers (B-doped, $200 \Omega \cdot \mathrm{cm}, 250 \mu \mathrm{m}$ ) were subjected to $\mathrm{QM}$ passivation as previously described in Section II and lifetime values were measured using $\mu \mathrm{PCD}$ and QSSPC, respectively. Wafers were then rinsed of quinhydrone using a four-beaker "methanol cascade" method [10], and the process of passivation, measurement, and rinsing was repeated twice without cleaning using an $\mathrm{HCl} / \mathrm{HF}$ process between passivations. An average of $8-10 \mu \mathrm{m}$ was then etched from each side of each wafer using a chemical polishing (CP) etching followed by $\mathrm{HCl} / \mathrm{HF}$ cleaning, after which the process of passivation, measurement, and rinsing was repeated three times, again without cleaning using an $\mathrm{HCl} / \mathrm{HF}$ process between passivations. Another CP etching removed an average of $8-10 \mu \mathrm{m}$ from each side of each wafer, followed by $\mathrm{HCl} / \mathrm{HF}$ cleaning. Again the process of passivation, measurement, and rinsing was repeated three times without cleaning using an $\mathrm{HCl} / \mathrm{HF}$ process between passivations (see Fig. 6). Lifetime values decreased with each repeated passivation and were then restored to near the original value after a $\mathrm{CP}$ etching and $\mathrm{HCl} / \mathrm{HF}$ cleaning. The $\mathrm{FZ}$ wafers showed an especially marked decrease in lifetime values with repeated passivation. The decrease in lifetime values is again attributed to quinhydrone residues that penetrate the wafer surface and stay on the wafer even after a methanol rinsing step. The contaminated surface is then removed by the CP etching step. An analogous experiment conducted with IE passivation 
TABLE I

QSSPC LIFETIME MEASUREMENTS (INJECTION $2 \times 10^{15} \mathrm{~cm}^{-3}$; QUASISTEADY-STATE MODE) OF DIELECTRICALLY PASSIVATED me SILICON WAFERS

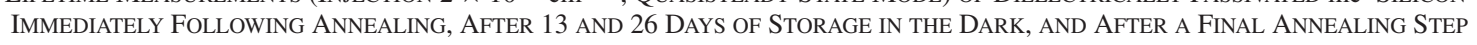

\begin{tabular}{|c|c|c|c|c|c|}
\hline $\begin{array}{c}\text { Wafer } \\
\text { thickness }(\mu s)\end{array}$ & $\begin{array}{c}\text { Passivation } \\
\text { type }\end{array}$ & $\begin{array}{c}\text { Lifetime Value } \\
(\mu \mathrm{s}) \text {, day } 1\end{array}$ & $\begin{array}{c}\text { Lifetime Value } \\
(\mu \mathrm{s}) \text {, day } 13\end{array}$ & $\begin{array}{l}\text { Lifetime Value ( } \mu \mathrm{s}) \text {, } \\
\text { day } 26\end{array}$ & $\begin{array}{c}\text { Lifetime value ( } \mu s) \text {, day } \\
26 \text {, after anneal }\end{array}$ \\
\hline 180 & $\mathrm{Al}_{2} \mathrm{O}_{3}$ & 41.6 & 33.6 & & \\
\hline 180 & a-Si & 27.0 & 20.2 & 19.4 & 23.1 \\
\hline 300 & $\mathrm{SiN}_{\mathrm{x}}$ & 46.4 & 47.9 & & \\
\hline
\end{tabular}

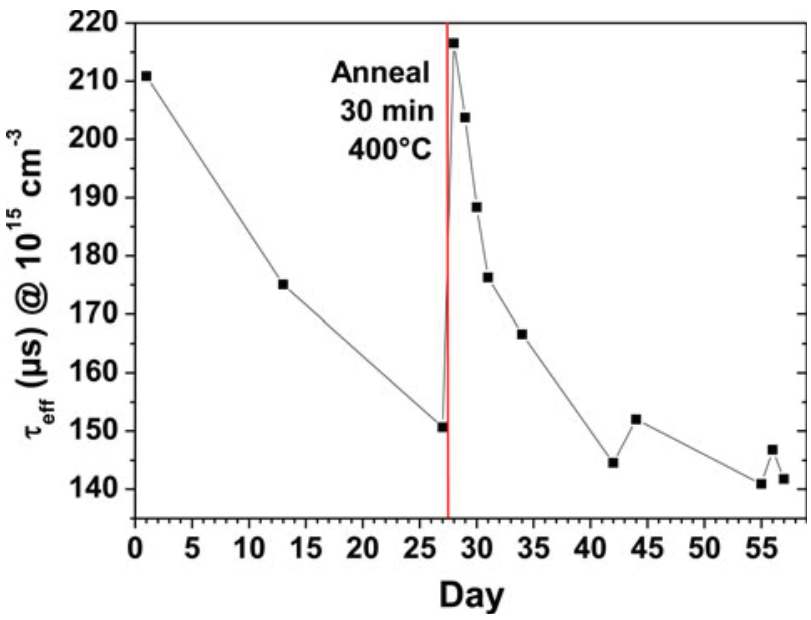

Fig. 4. Average QSSPC lifetime measurements (quasisteady-state mode) of 11 pregettered mc wafers that are passivated with $\mathrm{Al}_{2} \mathrm{O}_{3}$ and annealed at $400{ }^{\circ} \mathrm{C}$ on day one and measured over a period of 57 days. Wafers were stored in darkness between measurements. Wafers were annealed a second time at $400{ }^{\circ} \mathrm{C}$ on day 28.

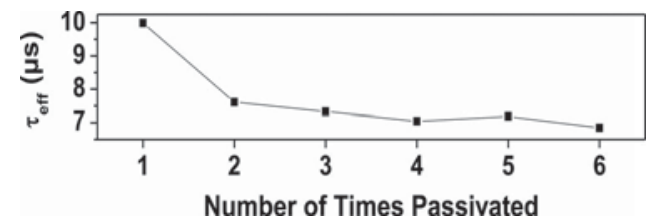

Fig. 5. $\mu \mathrm{PCD}$ average measured lifetime values of an EFG silicon wafer subjected to a QM passivation, measurement, and rinsing process six times in succession.

showed a similar decreasing lifetime trend on mc wafers that were similar to the mc wafers in Fig. 6.

\section{B. Influence on the Bulk Material}

Each of a set of five neighboring mc wafers (B-doped, 1 $\Omega \cdot \mathrm{cm}, 300$ and $180 \mu \mathrm{m}$ ) was passivated by $\mathrm{Al}_{2} \mathrm{O}_{3}, \mathrm{a}-\mathrm{Si}, \mathrm{SiN}_{x}$, IE, or QM, respectively. Minority charge carrier lifetimes were measured using QSSPC at an injection level of $10^{15} \mathrm{~cm}^{-3}$. Spatially resolved measurements were obtained by photoluminescence imaging (PLI) [11]. Because of influence from the crucible during block casting, each wafer exhibited two distinct halves: the first half with a gradient of lifetime values from 0 to $20 \mu$ s starting from the top edge of the wafer and moving toward the middle and the second half with lifetime values many times higher (see Fig. 7). In comparison with the neighboring wafers in this set which were not passivated with $\mathrm{SiN}_{x}$,

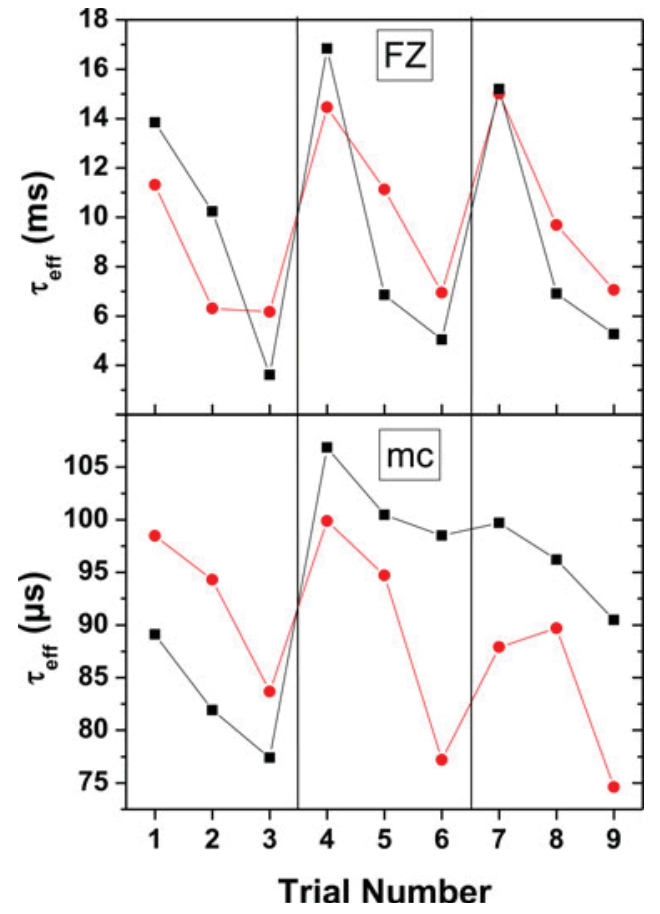

Fig. 6. QSSPC lifetime values (injection $10^{15} \mathrm{~cm}^{-3}$; transient mode) of two FZ wafers (top) and averaged $\mu$ PCD lifetime values of two mc wafers (bottom) that are subjected to three cycles of QM passivation, measurement, and rinsing, with a new wafer surface etched between each cycle. Vertical bars between points indicate $\mathrm{CP}$ etching between trials.

wafers passivated through the $\mathrm{SiN}_{x}$ deposition process at $450{ }^{\circ} \mathrm{C}$ showed a greater total amount of area with elevated lifetime values in the PLI images but displayed fewer and smaller areas of very high lifetime. Areas of high dislocation density also appeared to be more recombination active in wafers passivated with $\mathrm{SiN}_{x}$. These factors suggest internal gettering of defects e.g., by clustering of $\mathrm{Fe}_{i}$ in the highly contaminated regions of the wafer [12], [13] and release of impurities in the wafer areas of better quality [14] and/or hydrogenation of the Si bulk during deposition [15]. These effects can be attributed to the higher temperature $\operatorname{SiN}_{x}$ deposition process at $450{ }^{\circ} \mathrm{C}$.

The me wafer that was passivated with $\mathrm{SiN}_{x}$ (shown in Fig. 7) was subsequently stripped of its $\operatorname{SiN}_{x}$ passivation layer and repassivated with IE. Areas of increased recombination activity continued to show increased recombination activity and the wafer displayed lower lifetime values, as compared with a neighboring wafer passivated with IE and not subjected to the initial $\mathrm{SiN}_{x}$ deposition (see Fig. 7). This proves that the effects of 


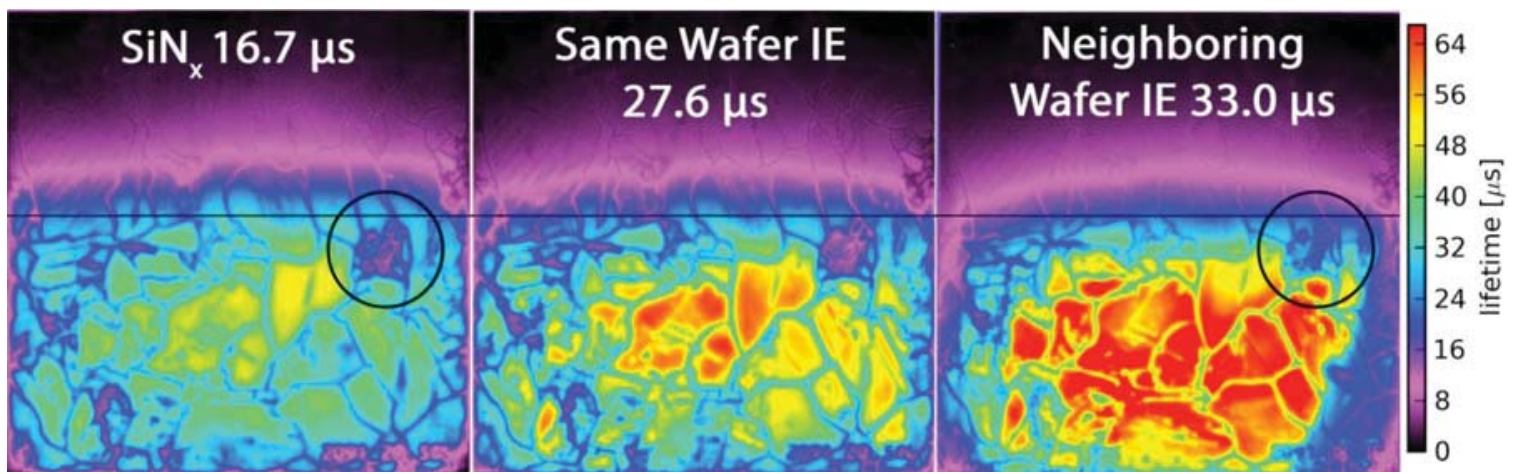

Fig. 7. PLI images show that (left) a $\mathrm{SiN}_{x}$ wafer stripped of its $\mathrm{SiN}_{x}$ layer and (middle) repassivated with IE shows increased recombination activity of grain boundaries and a lower lifetime value as compared with (right) a neighboring IE wafer not subjected to the initial SiN $\mathrm{N}_{x}$ deposition. Internal gettering because of higher temperature processes produces a larger area of moderately high lifetime values and increased recombination activity of grain boundaries in the SiN $x$ wafer, as compared with the neighboring wafer that is passivated with IE (see black circles).

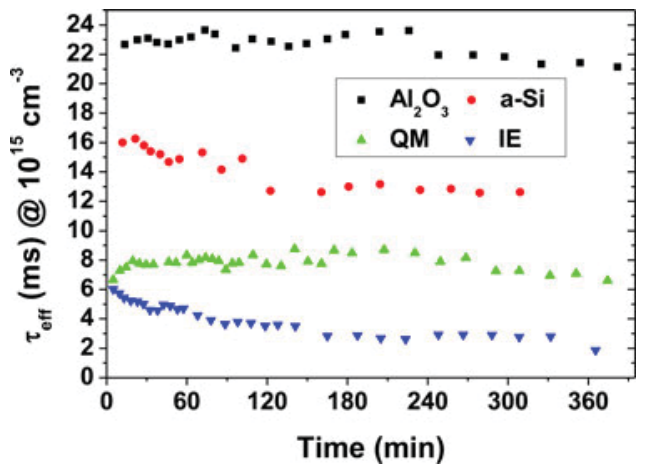

Fig. 8. Average QSSPC bulk minority carrier lifetime values (transient mode) of four sets of two FZ wafers using four different passivation methods. Lifetime measurements of $\mathrm{SiN}_{x}$ samples (not shown) exhibited average values of 3.3 (prefiring) and $6.2 \mathrm{~ms}$ (postfiring).

a high-temperature $\mathrm{SiN}_{x}$ deposition process directly affect the wafer bulk.

\section{Surface Passivation Quality}

To gather knowledge of the highest possible lifetime values obtainable with the passivation methods discussed in this paper, $10 \mathrm{FZ}$ wafers (B-doped, $200 \Omega \cdot \mathrm{cm}, 220 \mu \mathrm{m}$ ) were subjected to an RCA cleaning and, subsequently, passivated in groups of two by the dielectric passivation techniques $\mathrm{Al}_{2} \mathrm{O}_{3}$, a-Si, and $\mathrm{SiN}_{x}$ and the wet chemical passivation techniques QM and IE. The minority charge carrier lifetime values of all samples were obtained by QSSPC at an injection level of $10^{15} \mathrm{~cm}^{-3}$. The lifetime values of the $\mathrm{SiN}_{x}$ samples were measured once before and several times after firing them at $850{ }^{\circ} \mathrm{C}$ in a belt furnace (same step as used for the processing of industrial type solar cells). The time-resolved minority charge carrier lifetime values of the $\mathrm{Al}_{2} \mathrm{O}_{3}$ and a-Si samples were measured directly after an anneal step as described previously. The time-resolved minority charge carrier lifetime values of the QM and IE samples were measured directly after passivation. The average values of each two-sample set, except for the $\mathrm{SiN}_{x}$ set, are shown in Fig. 8 . Minority charge carrier lifetime values (not time-resolved) of $\mathrm{SiN}_{x}$ samples reached an average prefiring value of $3.3 \mathrm{~ms}$
TABLE II

PASSIVATION TeChNiQues USING SPECIFIC CONDITIONS That ARE DESCRIBED IN THIS PAPER RATED RELATIVE TO EACH OTHER ON THREE KEY CRITERIA

\begin{tabular}{|r|c|c|c|c|c|}
\cline { 2 - 6 } \multicolumn{1}{l|}{} & $\mathrm{Al}_{2} \mathrm{O}_{3}$ & $\mathrm{a}-\mathrm{Si}$ & $\mathrm{SiN}_{\mathrm{x}}$ & $\mathrm{QM}$ & $\mathrm{IE}$ \\
\hline $\begin{array}{r}\text { Passivation } \\
\text { stability }\end{array}$ & $0 ?$ & $\mathbf{0}$ & + & 0 & - \\
\hline $\begin{array}{r}\text { Surface } \\
\text { passivation } \\
\text { quality }\end{array}$ & + & 0 & 0 & 0 & - \\
\hline $\begin{array}{r}\text { Minimal } \\
\text { rhange to } \\
\text { wafer bulk }\end{array}$ & 0 & 0 & - & 0 & 0 \\
\hline $\begin{array}{r}\text { Suitability } \\
\text { for mono-Si }\end{array}$ & + & + & 0 & 0 & - \\
\hline $\begin{array}{r}\text { Suitability } \\
\text { for multi-Si }\end{array}$ & 0 & 0 & - & + & + \\
\hline
\end{tabular}

"+" is best, " 0 " is fair, and "-.-" is worst. The passivation stability of $\mathrm{Al}_{2} \mathrm{O}_{3}$ is rated as " 0 ?" because it is not yet known if the degradation seen in Fig. 4 is a surface or a bulk effect.

and an average postfiring value of $6.2 \mathrm{~ms}$ (no degradation was observed after firing).

\section{CONCLUSION}

Each passivation method that was investigated here offers differing degrees of passivation stability, surface passivation quality, and altering impact on defect distribution in the wafer bulk, making no one method ideal for all p-type wafer characterization passivation applications. Table II shows a summary of the strengths and weaknesses of the passivation methods investigated. a-Si and, particularly, $\mathrm{Al}_{2} \mathrm{O}_{3}$ achieve high effective lifetime values but suffer from surface passivation degradation within hours and days, respectively. As used here, $\mathrm{SiN}_{x}$ shows no signs of degradation but suffers from lower surface passivation quality compared with the other dielectric layers under investigation and causes significant changes to the wafer bulk, making it particularly poorly suited for mc material, where bulk changes can be exceedingly detrimental. QM and IE passivation are room-temperature processes that induce minimal negative effects on the wafer bulk and provide relatively high surface passivation quality. QM and IE provide, however, only 
temporary passivation properties, are not suitable for long-term wafer passivation, and were shown to cause degradation to the region of the wafer near to the surface.

Finally, we would like to note that there are many ways to deposit passivating layers (especially a-Si and $\mathrm{SiN}_{x}$ ) on crystalline Si surfaces, resulting in different refractive indices etc., and, therefore, different surface passivation properties. The results presented in this paper are, therefore, valid only for the specific experimental conditions chosen for this study, which are given in the text.

\section{REFERENCES}

[1] B. Hoex, J. Schmidt, P. Pohl, M. C. M. van de Sanden, and W. M. M. Kessels, "Silicon surface passivation by atomic layer deposited $\mathrm{Al}_{2} \mathrm{O}_{3}$," J. Appl. Phys., vol. 104, pp. 044903-1-044903-12, 2008.

[2] A. Aberle, "Overview on SiN surface passivation of crystalline silicon solar cells," Solar Energy Mater. Solar Cells, vol. 65, pp. 239-248, 2001.

[3] H. Plagwitz, B. Terheiden, and R. Brendel, "Staebler-Wronski-like formation of defects at the amorphous-silicon-crystalline silicon interface during illumination," J. Appl. Phys., vol. 103, pp. 094506-1-094506-4, 2008.

[4] T. S. Horanyi, T. Pavelka, and P. Tüttö, "In situ bulk lifetime measurement on silicon with a chemically passivated surface," Appl. Surf. Sci., vol. 63, pp. 306-311, 1993.

[5] A. W. Stephens and M. A. Green, "Effectiveness of 0.08 molar iodine in ethanol solution as a means of chemical surface passivation for photoconductance decay measurements," Solar Energy Mater. Solar Cells, vol. 45, pp. 255-265, 1997.

[6] H. Takato, I. Sakata, and R. Shimokawa, "Quinhydrone/methanol treatment for the measurement of carrier lifetimes in silicon substrates," Jpn. J. Appl. Phys., vol. 41, pp. L870-L872, 2002.

[7] B. Chhabra, S. Bowden, R. L. Opila, and C. B. Honsberg, "High effective minority carrier lifetime on silicon substrates using quinhydronemethanol passivation," Appl. Phys. Lett., vol. 96, pp. 063502-1-063502-3, 2010 .

[8] W. Kern, "The evolution of silicon wafer cleaning technology," J. Electrochem. Soc., vol. 137, no. 6, pp. 1887-1892, 1990.

[9] W. Kern and D. Puotinen, "Cleaning solutions based on hydrogen peroxide for use in silicon semiconductor technology," RCA Rev., vol. 31, pp. 187206, 1970.

[10] M. Solcansky, M. Machacek, J. Bousek, and A. Poruba, "Chemical passivation of a silicon surface for minority carrier bulk-lifetime measurements," in Proc. 24th Eur. Photovoltaic Solar Energy Conf., Hamburg, Germany, 2009, pp. 1669-1672.

[11] T. Trupke, R. A. Bardos, M. C. Schubert, and W. Warta, "Photoluminescence imaging of silicon wafers," Appl. Phys. Lett., vol. 89, pp. 0441071-044107-3, 2006.

[12] R. Krain, S. Herlufsen, and J. Schmidt, "Internal gettering of iron in multicrystalline silicon at low temperature," Appl. Phys. Lett., vol. 93, no. 15, pp. 152108-1-152108-3, 2008.

[13] H. Habenicht, M. C. Schubert, A. Richter, and W. Warta, "Impact of $\mathrm{SiN}_{\mathrm{X}}: \mathrm{H}$ and $\mathrm{Al}_{2} \mathrm{O}_{3}$ surface passivation on interstitial iron concentration and carrier lifetime in mc-silicon wafers," in Proc. 24th Eur. Photovoltaic Solar Energy Conf., Hamburg, Germany, 2009, pp. 2266-2269.
[14] H. Habenicht, S. Riepe, O. Schultz, and W. Warta, "Out-diffusion of metal from grain boundaries in multicrystalline silicon during thermal processing," in Proc. 22nd Eur. Photovoltaic Solar Energy Conf., Milan, Italy, 2007, pp. 1519-1523.

[15] B. Herzog, G. Hahn, M. Hofmann, I. G. Romijn, and A. W. Weeber, "Bulk hydrogenation in $\mathrm{mc}-\mathrm{Si}$ by PECVD $\mathrm{SiN}_{\mathrm{x}}$ deposition using direct and remote plasma," in Proc. 23rd Eur. Photovoltaic Solar Energy Conf., Valencia, Spain, 2008, pp. 1863-1866. 